\title{
Topographic Study of Corneal Periphery in Selected Rheumatic Diseases
}

\section{Ahmed I. Kamel ${ }^{1}$, Mahmoud M. Khalil ${ }^{1}$, Hatem G. Abdallah ${ }^{2}$, Mohammed H. Ragheb ${ }^{1 *}$}

Department of Ophthalmology, Department of Rheumatology and Rehabilitation,Faculty of Medicine, Al-Azhar University

*Corresponding Author: Mohammed H. Ragheb, Mobile: (+20)01014481889, E-mail: mohammedhamed2018@ yahoo.com

\begin{abstract}
Background: many of autoimmune diseases associated with ophthalmological complication, such as Peripheral ulcerative keratitis.

Objective: to evaluate the potential changes in the peripheral corneal thickness in selected rheumatic autoimmune diseases.

Patients and Methods: a case control study was been held in Al-Azhar University Hospitals on 80 eyes for 40 patients and subjects. The patients and subjects was been examined by Pentacam examination.

Results: as regard peripheral corneal thickness, the mean peripheral thickness of RA patients was $668.6 \pm 32.1$ micron, the mean peripheral thickness of SLE patients was $667.5 \pm 34.8$ micron, the mean peripheral thickness of SNA patients was $637.8 \pm 86.7$ micron and the mean peripheral thickness of control patients was $681.2 \pm 12.8$ micron (p-value $=0.045$ ).
\end{abstract}

Conclusion: the peripheral corneal thickness was thinner in autoimmune patients than in normal subjects.

Keywords: peripheral keratitis, autoimmune diseases, pentacam.

\section{INTRODUCTION}

A host defensive mechanism against disease, the immune system consists of numerous biological components and mechanisms ${ }^{(\mathbf{1})}$. Rheumatoid arthritis, systemic lupus erythematosus, juvenile rheumatoid arthritis, and sero-negative arthritis are only a few of the many systemic autoimmune illnesses that have ocular manifestation. ${ }^{(2)}$.

The common ocular manifestations of systemic autoimmune diseases include tear deficiency leading to dry eyes, or keratoconjunctivitissicca, episcleritis, scleritis, synechiae and pupillary miosis, retinal vasculitis and peripheral ulcerative keratitis $(\mathrm{PUK})^{(\mathbf{3})}$. Peripheral ulcerative keratitis (PUK) is a group of inflammatory diseases whose final common pathway is peripheral corneal thinning ${ }^{(4)}$.

Examining the cornea's shape, curvature, power, and thickness using corneal topography is exceptionally helpful (5). Rotating Scheimpflug cameras, such as the Pentacam, is a non-invasive objective device that allows evaluation of the cornea ${ }^{(6)}$. AIM OF THE WORK

To evaluate the potential changes in the peripheral corneal thickness in selected rheumatic autoimmune diseases.

\section{PATIENTS AND METHODS}

This study was been ethically approved by Al-Azhar Committee as a case control study.It was been held in Al-Azhar University Hospitals. The study was carried out on 80 eyes for 40 patients and subjects to compare the peripheral corneal changes in selected rheumatic autoimmune diseases with each other and with healthy persons, by using Pentacam examination, (SIRIUS @ 3D Rotating Schimflug camera \& topography system).

Rheumatic patients were taken by random sample from the Rheumatology clinics and department in Al-Azhar University Hospitals and they were matched by a control group.

\section{Patients and subjects were categorized into 4 groups:}

Group (1): Twenty eyes of normal subjects.

Group (2): Twenty eyes in patients with rheumatoid arthritis.

Group (3): Twenty eyes in patients with systemic lupus. Group (4): Twenty eyes in patients with seronegative arthritis.

\section{Written informed consent:}

The academic and ethical committee of Al-Azhar University approved the work. Each patient completed a written informed consent form to accept the procedure.

\section{Inclusion criteria:}

- Age: 18-60 years.

- Patients with definite rheumatic autoimmune disease (Systemic lupus, rheumatoid arthritis, and seronegative arthropathy includes psoriasis, ankylosing spondylitis \& juvenile rheumatoid arthritis).

- Autoimmune disease diagnosed patient at least 6 months.

\section{Exclusion criteria:}

- Patients with corneal opacity or scar other than that caused by rheumatic autoimmune diseases.

- Patients with glaucoma.

- Patients with history of ocular surgery.

- Patients with active uveitis.

- Contact lens users.

- Severe dry eye.

- Pregnancy.

- Any chronic use of eye drops other than tears substitutions.

All patient and subjects were subjected to the followings: 
1. Ophthalmological examination: History taking, includes: name, age, gender, type of autoimmune disease period andmanifestation ofassociated, Assessment of uncorrected and best corrected visual acuity using Snellen's chart, Measuring of IOP using Goldman applanation tonometry, Slit lamp examination for assessment peripheral corneal changes as thickness, ulceration, dryness and other abnormality, Tear film break up time. (TBUT), Binocular indirect ophthalmoscope examination and Pentacam examination, (SIRIUS @3D Rotating Schimflug camera \& topography system).

2. Laboratory investigation: Complete blood picture, Erythrocyte sedimentation rate (ESR), Specific laboratory tests for each selected rheumatic autoimmune disease.

\section{Statistical analysis}

The Statistical Program for Social Science (SPSS) version 15.0 was used to analyse the data. Quantitative information was presented as mean and standard deviation (SD). The frequency and percentage of the qualitative data were expressed.

The following tests were done:

- When comparing more than two means, a one-way analysis of variance (ANOVA) was utilized.

- When comparing non-parametric data, the Chi-square test was utilized.

\section{Probability of P-value:}

P-values 0.05 or lower was regarded as significant.

$\mathrm{P}$-values lower than 0.001 were regarded as extremely significant.

- P-values higher than 0.05 were regarded as insignificant.

- P: statistical difference between all studied groups.

- P1: statistical difference between RA group and Control group.

- P2: statistical difference between SLE group and Control group.

- P3: statistical difference between SNA group and Control group.

\section{RESULTS}

Table (1): Comparison between studied groups as regard age

\begin{tabular}{|c|c|c|c|c|c|c|}
\hline \multicolumn{2}{|l|}{ Variables } & $\begin{array}{c}\text { RA } \\
(\mathbf{N}=\mathbf{2 0})\end{array}$ & $\begin{array}{c}\text { SLE } \\
(\mathbf{N}=\mathbf{2 0})\end{array}$ & $\begin{array}{c}\text { SNA } \\
(\mathbf{N}=\mathbf{2 0})\end{array}$ & $\begin{array}{l}\text { Control } \\
(\mathbf{N}=\mathbf{2 0})\end{array}$ & P-value \\
\hline \multirow{2}{*}{ Age (years) } & Mean & 54.5 & 43.0 & 30.5 & 37.9 & \multirow{2}{*}{$<0.001 *$} \\
\hline & \pm SD & 7.9 & 8.2 & 13.9 & 0.0 & \\
\hline
\end{tabular}

*: p-value $<0.001$ is considered highly significant.

Table (1) shows highly statistical significant difference (p-value $<\mathbf{0 . 0 0 1}$ ) between studied groups as regard age. Mean age of RA patients was $54.5 \pm 7.9$ years, Mean age of SLE patients was 43.0 \pm 8.2 years, Mean age of SNA patients was $30.5 \pm 13.9$ years while it was $37.9 \pm 5.4$ years in control group ( $\mathrm{p}$-value $<0.001$ ).

Table (2): Comparison between studied groups as regard sex

\begin{tabular}{|c|c|c|c|c|c|c|}
\hline \multicolumn{2}{|c|}{ Variables } & RA $(\mathbf{N}=20)$ & SLE $(\mathbf{N}=20)$ & SNA $(\mathbf{N}=20)$ & Control $(\mathrm{N}=\mathbf{2 0})$ & P-value \\
\hline \multirow{2}{*}{ Sex } & Male & $0(0 \%)$ & $2(10 \%)$ & $0(0 \%)$ & $2(10 \%)$ & \multirow{2}{*}{0.24} \\
\hline & Female & $20(100 \%)$ & $18(90 \%)$ & $20(100 \%)$ & $18(90 \%)$ & \\
\hline
\end{tabular}

Table (2) shows no statistical significant difference (p-value $>0.05$ ) between studied groups as regard sex. There were $0(0 \%)$ male and $20(100 \%)$ female in RA patients, $2(10 \%)$ male and $18(90 \%)$ female in SLE patients, $0(0 \%)$ male and $20(100 \%)$ female in SNA patients while there were $2(10 \%)$ male and $18(90 \%)$ female in control patients, (p-value $=0.24)$.

Table (3): Comparison between studied groups as regard disease duration and treatment

\begin{tabular}{|c|c|c|c|c|c|}
\hline \multicolumn{2}{|l|}{ ariables } & $\begin{array}{c}\text { RA } \\
(\mathbf{N}=\mathbf{2 0})\end{array}$ & $\begin{array}{c}\text { SLE } \\
(\mathbf{N}=\mathbf{2 0})\end{array}$ & $\begin{array}{c}\text { SNA } \\
(\mathbf{N}=\mathbf{2 0})\end{array}$ & P-value \\
\hline \multirow{2}{*}{ Disease duration (years) } & Mean & 21.1 & 15.2 & 8.0 & \multirow{2}{*}{$<0.001 *$} \\
\hline & \pm SD & 6.9 & 14.1 & 5.8 & \\
\hline \multirow{3}{*}{ Treatment } & Methotrexate & $6(30 \%)$ & $6(30 \%)$ & $2(10 \%)$ & \multirow{3}{*}{0.4} \\
\hline & Cortisone & $9(45 \%)$ & $9(45 \%)$ & $14(70 \%)$ & \\
\hline & NSAID & $5(25 \%)$ & $5(25 \%)$ & $4(20 \%)$ & \\
\hline \multirow{2}{*}{ Duration of TTT (years) } & Mean & 13.2 & 12.5 & 5.3 & \multirow{2}{*}{$<0.001 *$} \\
\hline & \pm SD & 6.7 & 12.0 & 3.8 & \\
\hline
\end{tabular}

*: p-value $<0.001$ is considered highly significant. 
Table (3) illustrates comparisons between the groups under study with regard to the medications and course of the diseases. Regarding disease duration and treatment period, there was a very statistically significant difference (p-value 0.001) between the analysed groups.

As regard disease duration, mean disease duration of RA patients was $21.1 \pm 6.9$ years, mean disease duration of SLE patients was $15.2 \pm 14.1$ years and mean disease duration of SNA patients was $8.0 \pm$ 5.8 years ( $\mathrm{p}$-value $<0.001$ ).

As regard treatment, there were 6 patients $(30 \%)$ treated by methotrexate, 9 patients $(45 \%)$ treated by cortisone and 5 patients (25\%) treated by NSAID in RA group. There were 6 patients $(30 \%)$ treated by methotrexate, 9 patients (45\%) treated by cortisone and 5 patients $(25 \%)$ treated by NSAID in SLE group. There were 2 patients $(10 \%)$ treated by methotrexate, 14 patients (70\%) treated by cortisone and 4 patients (20\%) treated by NSAID in SNA group.

As regard treatment duration, mean treatment duration of RA patients was $13.2 \pm 6.7$ years, mean treatment duration of SLE patients was $12.5 \pm 12.0$ years and mean treatment duration of SNA patients was $5.3 \pm 3.8$ years $(\mathrm{p}$-value $<0.001)$.

\section{Table (4): Comparison between studied groups as regard corneal thickness}

\begin{tabular}{|c|c|c|c|c|c|c|}
\hline \multicolumn{2}{|l|}{ Variables } & $\begin{array}{c}\text { RA } \\
(\mathbf{N}=\mathbf{2 0})\end{array}$ & $\begin{array}{c}\text { SLE } \\
(\mathbf{N}=\mathbf{2 0})\end{array}$ & $\begin{array}{c}\text { SNA } \\
\mathbf{N}=\mathbf{2 0}\end{array}$ & $\begin{array}{l}\text { Control } \\
(\mathrm{N}=21)\end{array}$ & P-value \\
\hline \multirow{2}{*}{$\begin{array}{l}\text { Central } \\
\text { (micron) }\end{array}$} & Mean & 520.4 & 502.3 & 504.8 & 548.5 & $P<0.001 *$ \\
\hline & \pm SD & 23.7 & 24.7 & 16.4 & 25.4 & $\begin{array}{l}\text { P1 }<0.001 * \\
\text { P2 }<0.001 * \\
\text { P3 }<0.001 *\end{array}$ \\
\hline \multirow{2}{*}{$\begin{array}{l}\text { Peripheral } \\
\text { (micron) }\end{array}$} & Mean & 668.6 & 667.5 & 637.8 & 681.2 & $\mathrm{P}=0.045$ \\
\hline & \pm SD & 32.1 & 34.8 & 86.7 & 12.8 & $\begin{array}{l}\mathrm{P} 1=0.42 \\
\mathrm{P} 2=0.38 \\
\mathbf{P 3}=\mathbf{0 . 0 0 7}\end{array}$ \\
\hline \multirow[t]{2}{*}{$\mathrm{C} / \mathrm{P}$ ratio } & Mean & 0.78 & 0.75 & 0.8 & 0.8 & $\mathrm{P}=0.083$ \\
\hline & \pm SD & 0.03 & 0.04 & 0.13 & 0.03 & $\begin{array}{l}\mathrm{P} 1=0.29 \\
\mathbf{P 2}=\mathbf{0 . 0 3 5} \\
\mathrm{P} 3=0.86\end{array}$ \\
\hline
\end{tabular}

$*$ : p-value $<0.001$ is considered highly significant.

Table (4) shows comparison between studied groups as regard corneal thickness. There was highly statistical significant difference ( $p$-value $<0.001$ ) between studied groups as regard central while there was no statistical significant difference ( $p$-value $>0.05$ ) between studied groups as regard peripheral corneal thickness and also $\mathrm{C} / \mathrm{P}$ ratio.

As regard central corneal thickness, the mean central thickness of RA patients was $520.4 \pm 23.7$ micron, the mean central thickness of SLE patients was $502.3 \pm 24.7$ micron, the mean central thickness of SNA patients was $504.8 \pm 16.4$ micron and the mean central thickness of control patients was $548.5 \pm 25.4$ micron (p-value $<0.001$ ).

As regard peripheral corneal thickness, the mean peripheral thickness of RA patients was $668.6 \pm$
32.1 micron, the mean peripheral thickness of SLE patients was $667.5 \pm 34.8$ micron, the mean peripheral thickness of SNA patients was $637.8 \pm 86.7$ micron and the mean peripheral thickness of control patients was $681.2 \pm 12.8$ micron $(\mathrm{p}$-value $=0.045)$.

As regard $\mathrm{C} / \mathrm{P}$ ratio, the mean ratio of $\mathrm{RA}$ patients was $0.78 \pm 0.03$, the mean ratio of SLE patients was $0.75 \pm 0.04$, the mean ratio of SNA patients was 0.8 \pm 0.13 and the mean ratio of control patients was $0.8 \pm$ 0.03 ( $\mathrm{p}$-value $=0.083)$.

Table (5): Comparison between studied groups as regard $\mathrm{K}(\max )$ and $\mathrm{K}(\min )$

\begin{tabular}{|c|c|c|c|c|c|c|}
\hline \multicolumn{2}{|c|}{ Variables } & $\begin{array}{c}\text { RA } \\
(\mathbf{N}=\mathbf{2 0})\end{array}$ & $\begin{array}{c}\text { SLE } \\
\mathbf{N}=\mathbf{2 0}\end{array}$ & $\begin{array}{c}\text { SNA } \\
(\mathbf{N}=\mathbf{2 0}\end{array}$ & $\begin{array}{l}\text { Control } \\
(\mathbf{N}=\mathbf{2 0})\end{array}$ & $\begin{array}{c}\text { P- } \\
\text { value }\end{array}$ \\
\hline K (Max) & Mean & 44.9 & 47.6 & 45.6 & 43.08 & $<0.001$ \\
\hline & & 1.4 & 2.6 & 1.2 & 0.52 & $*$ \\
\hline & Mea & 42.7 & 44.02 & 44.07 & 43.6 & 0.031 \\
\hline (Diopter) & $\pm \mathrm{SD}$ & 1.4 & 1.9 & 1.5 & 1.6 & $* *$ \\
\hline
\end{tabular}

*: p-value $<0.001$ is considered highly significant.

**: p-value $<0.05$ is considered significant.

Table (5) shows comparison between studied groups as regard $\mathrm{K}$ (man) \& $\mathrm{K}(\mathrm{min})$. There was highly statistical significant difference (p-value $<0.001)$ between studied groups as regard $\mathrm{K}$ (max), while there is statistically significant difference (p-value $<\mathbf{0 . 0 5})$ between studied groups as regard $\mathrm{K}$ ( $\mathrm{min}$ ).

As regard K (max), the mean $\mathrm{K}(\max )$ of RA patients was $44.9 \pm 1.4$ diopter, the mean thinnest location of SLE patients was $47.6 \pm 2.6$ diopter, the mean $\mathrm{K}(\max )$ of SNA patients was $45.6 \pm 1.2$ diopter and the mean $\mathrm{K}(\max )$ of control patients was $43.08 \pm$ 0.52 diopter (p-value $<\mathbf{0 . 0 0 1})$.

As regard $\mathrm{K}$ (min), the mean $\mathrm{K}$ (min) of $\mathrm{RA}$ patients was $42.7 \pm 1.4$ diopter, the mean $\mathrm{K}$ (min) of SLE patients was $44.02 \pm 1.9$ diopter, the mean $\mathrm{K}$ (min) of SNA patients was $44.07 \pm 1.5$ diopter and the mean $\mathrm{K}$ (min) of control patients was $43.6 \pm 1.6$ diopter (pvalue $\mathbf{0} \mathbf{0 . 0 0 3})$.

\section{DISCUSSION}

An autoimmune illness is a condition that develops when the immune system reacts abnormally to healthy body parts. Autoimmune disorders come in at least 80 different varieties. Anyone can be affected by this ${ }^{(7)}$. Three persons per million per year are reported for PUK. Male and female populations are equally prevalent. Numerous autoimmune diseases have been associated with PUK ${ }^{(8)}$. According to our research, several autoimmune disorders and peripheral corneal thickness are positively correlated. (peripheral cornea was thinner in autoimmune disease patients more than non diseased persons). However, this correlation was statistically non-significant correlation.

As regard peripheral corneal thickness, the mean peripheral thickness of RA patients was $668.6 \pm 32.1$ micron, the mean peripheral thickness of SLE patients 
was $667.5 \pm 34.8$ micron, the mean peripheral thickness of SNA patients was $637.8 \pm 86.7$ micron and the mean peripheral thickness of control patients was $681.2 \pm 12.8$ micron ( $\mathrm{p}$-value $=0.045$ ). In Ryu et $\boldsymbol{a l} .{ }^{(9)}$ study, a total of 589 RA patients were included. PUK was identified in eight of those patients (five male, three female). Four out of every six PUK patients showed laterality. The reason that their results may have been significant while ours were not is that their study group included 589 eyes, which is much larger than our group ( 80 eyes).

In Liu et $\boldsymbol{a l} .{ }^{\left({ }^{10}\right)}$ study the Patients with RA had considerably thinner corneal thickness than the control group. But this study was done on patients with KCS in general and for KCS combined with autoimmune disease. Therefore, our results cannot be compared to his results.

In Anayol et al. ${ }^{(11)}$ Although the difference was statistically insignificant, the RA patients' central and thinnest corneal thickness measurements (544.436.79 m, 535.137.22 m) were lower than those of the control group (554.546.25 m, 547.686.34 m). This agreed with our study.

But In all ophthalmological criteria as IOP, visual acuity, corneal biomechanics and corneal thickness no statistical significant differences could be found, e.g. corneal thickness (RA: $584.95 \pm 37,44$ $\mu \mathrm{m}$ versus controls:571.81 $\pm 38.49, \mathrm{p}=0.13$ ).

While, in Gunes et al. ${ }^{(\mathbf{1 2})}$, In contrast to healthy persons, the CCT and PCT were thinner in RA patients. The clinical characteristics of the RA or dry eye tests did not significantly correlate with the corneal parameters, though. That may be due to using different methods in estimating peripheral corneal thickness in previous two studies. As in in Konstantopoulos $\boldsymbol{e t} \boldsymbol{a \boldsymbol { l } ^ { ( \mathbf { 5 } ) }}$ Orbscan II was used while

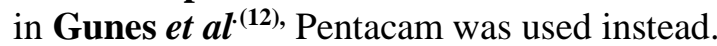

In Yazici et al..$^{(\mathbf{1 3}),}$ Ocular surface epitheliopathy owing to KCS, stromal keratitis (rare), and peripheral keratitis, notably marginal and segmental, are the most common corneal alterations in SLE., which agreed with our study on peripheral corneal changes in patients with SLE.

In Yazici et al. ${ }^{(13)}$, Compared to healthy controls, patients with SLE have different biomechanical characteristics of the cornea.This proved that there is corneal changes associated with SLE but this study compared corneal biomechanics of the cornea as a whole Therefore, our results - which involved peripheral cornea thickness- cannot be compared to his results.

In Rehal et al. ${ }^{(14)}$ corneal involvement in psoriasis is uncommon and typically results from conjunctival or eyelid problems like xerosis and trichiasis. Punctate epithelial keratitis is the most typical manifestation, however other diseases might present as shallow or deep opacities, stromal infiltrates, neovascularization, erosions, scarring, or even stromal melts.

\section{CONCLUSION}

Peripheral corneal thinning and the presence of autoimmune disorders were revealed to be significantly positively correlated. Since autoimmune patients' peripheral corneal thickness was thinner than that of healthy control.

\section{REFERENCES}

1. Borgelt L, O'Connell MB, Smith JA (2010): Women's Health Across the Lifespan: A Pharmacotherapeutic Approach. Available at: https://journals.sagepub.com/doi/abs/10.1345/aph.1P278.

2. Mehta S and Jiandani P (2007): Ocular features of hantavirus infection. Indian Journal of Ophthalmology, 55(5): 378-380.

3. Murray PI and Rauz S (2016): The eye and inflammatory rheumatic diseases: the eye and rheumatoid arthritis, ankylosing spondylitis, psoriatic arthritis. Best Practice \& Research Clinical Rheumatology, 30(5):802-825.

4. Silva BL, Cardozo JB and Marback P (2010): Peripheral ulcerative keratitis: a serious complication of rheumatoid arthritis. Rheumatology International, 30(9): 1267-1268.

5. Konstantopoulos A, Hossain $P$ and Anderson DF (2007): Recent advances in ophthalmic anterior segment imaging: a new era for ophthalmic diagnosis? $\mathrm{Br} \mathrm{J}$ Ophthalmol., 91:551-557.

6. Piñero DP, Nieto JC and Lopez-Miguel A (2012): Characterization of corneal structure in keratoconus. J Cataract Refract Surg., 38(12):2167-83.

7. Ruslan M (2007): Recognition of microorganisms and activation of the immune response.Nature, 449: 819-826.

8. Dana MR, Qian Y and Hamrah P (2000): Twenty-fiveyear panorama of corneal immunology: emerging concepts in the immunopathogenesis of microbial keratitis, peripheral ulcerative keratitis, and corneal transplant rejection. Cornea, 19(5):625-43.

9. Watanabe R, Ishii T, Yoshida M, Takada N, Yokokura S, Shirota Y, Fujii H, Harigae H(2015): Ulcerative keratitis in patients with rheumatoid arthritis in the modern biologic era: a series of eight cases and literature review. Int J Rheum Dis., 20(2):225-230.

10.Liu $Z$ and Pflugfelder SC (1999): Corneal thickness is reduced in dry eye. Cornea, 18:403-407.

11.Anayol MA, Bostancı B, Şekeroğlu MA, Şimşek M, Günaydın S, Yılmazbaş P (2017): Assessment of Corneal Densitometry in Rheumatoid Arthritis Patients. Turk J Ophthalmol., 47(3):125-129.

12. Gunes A, Inal EE, Tok L, Tok O (2015): Evaluation of central and peripheral corneal thicknesses in patients with rheumatoid arthritis. Arq Bras Oftalmol., 78(4):236-40.

13. Yazici AT, Kara N, Yüksel K, Altinkaynak H, Baz O et al. (2011): The biomechanical properties of the cornea in patients with systemic lupus erythematosus. Eye, 25: 10051009.

14. Rehal B, Modjtahedi BS, Morse LS, Schwab IR, Maibach HI (2011): Ocular psoriasis. J Am Acad Dermatol., 65: 1202-1212. 